\title{
Synthetic waterproofing membranes and auxiliary separating layers in the inverted flat roof. Pressure effect on the degradation
}

\author{
A. Pedrosa ${ }^{a} \bowtie$, M. Del Río ${ }^{a}$ \\ a. Escuela Técnica Superior de Edificación de Madrid,Universidad Politécnica de Madrid (Madrid, Spain)
}

$\triangle$ a.pedrosa.go@gmail.com

\begin{abstract}
Flat roofs are inverted when the insulation material is placed over the waterproofing membrane. This widely-used constructive system sets materials which may interact easily with each other causing their deterioration. The incompatibilities and the materials that may interact with each other are not completely described, the elements currently used to separate the materials are not totally efficient to avoid deterioration. This paper intends to enlarge the knowledge regarding the materials that are incompatible for inverted flat roofs, the conditions were interactions take place and the efficiency of some alternative solutions to separate the materials. The ethylene propylene diene monomer (EPDM) waterproofing membranes are incompatible with the extruded polystyrene (XPS). The interactions between incompatible materials increase with the pressure.
\end{abstract}

KEYWORDS: Polymer; Inverted flat roof; durability; synthetic waterproofing membrane; single ply membrane

Citation/Citar como: Pedrosa, A.; Del Río, M. (2018) Synthetic waterproofing membranes and auxiliary separating layers in the inverted flat roof. Pressure effect on the degradation. Mater. Construcc. 68 [331], e167 https://doi. org/10.3989/mc.2018.07617

RESUMEN: Membranas sintéticas impermeables y capas auxiliares separadoras en la cubierta plana invertida. Efecto de la presión sobre la degradación. Las cubiertas planas son invertidas cuando el material aislante se coloca sobre la membrana impermeable. Este sistema constructivo ampliamente utilizado emplea materiales que pueden interactuar con facilidad entre ellos, produciendo deterioro. Las incompatibilidades y los materiales que pueden interactuar no se han descrito completamente, los elementos utilizados actualmente para separar los materiales no son totalmente eficientes para evitar el deterioro. Este artículo pretende aumentar el conocimiento acerca de que materiales son incompatibles en la cubierta invertida plana, las condiciones para que las interacciones se den, y la eficiencia de algunas alternativas para separar materiales. Las membranas impermeables de etileno propileno monómero dieno (EPDM) son incompatibles con el poliestireno extrusionado (XPS). Las interacciones entre materiales incompatibles aumentan con la presión.

Palabras clave: Polímero; Cubierta plana invertida; durabilidad; membrana sintética impermeable; membrana monocapa

ORCID ID: A. Pedrosa (http://orcid.org/0000-0002-7477-6288); M. Del Río (http://orcid.org/0000-0002-4106-4233)

Copyright: (C) 2018 CSIC. This is an open-access article distributed under the terms of the Creative Commons Attribution 4.0 International (CC BY 4.0) License 


\section{INTRODUCTION}

The roof is part of the outer envelope of the buildings, and thus it must be able to protect and isolate indoor environments. The roof is located at the top of a building, so in addition to the above, it has to be an efficient cover for precipitation (rain, snow or hail).

The flat roof can be defined as a roof with a slope lower than $5 \%$. Consequently a flat roof needs to be waterproofed -to guarantee the tightness of the interior space-, but also isolated to keep comfortable temperatures inside the building.

Frequently, the insulation material is placed over the waterproofing membrane resulting in the inverted flat roof. This constructive system is broadly used.

In this type of flat roof, the insulation material limits the thermal variations of the waterproofing membrane (which is the most important material of a flat roof), so the insulation material protects the membrane from thermal degradation. This is the main issue explaining the reason why inverted flat roofs are widely used.

The inverted flat roof preserves the waterproofing membrane from thermal oscillations, so in theory this constructive system enlarges the life cycle of waterproofing membranes and consequently of the complete flat roof. However this consideration does not take into account the interactions between the materials which may cause deterioration.

\begin{tabular}{|ll|}
\hline \multicolumn{2}{l|}{ Nomenclature } \\
ASTM & American Society for Testing and Materials \\
EPDM & Ethylene Propylene Diene Monomer \\
ISO & International Organization for Standardization \\
PVC-P & Plasticized Polyvinyl Chloride \\
RSD $\%$ & Relative standard deviation in percentage \\
SEM & Scanning electron microscope \\
TPO & Thermoplastic Polyolefin (also FPO) \\
UNE & Spanish Association for Standardization \\
XPS & Extruded Polystyrene \\
\hline
\end{tabular}

Figure 1 shows the different materials comprising a stone-ballasted inverted flat roof.

The elements used nowadays to separate materials in the inverted flat roof are the auxiliary separating layers which are normally geo-textiles. The most frequents geo-textiles are made of polyester or polypropylene, as they are good materials to minimize the interactions and incompatibilities even in refurbishment of flat roofs (1). However, polyester geotextiles do not offer good resistance to the alkalinity of the cement, so they are especially used in gravel ballasted and green flat roofs. Basically, auxiliary

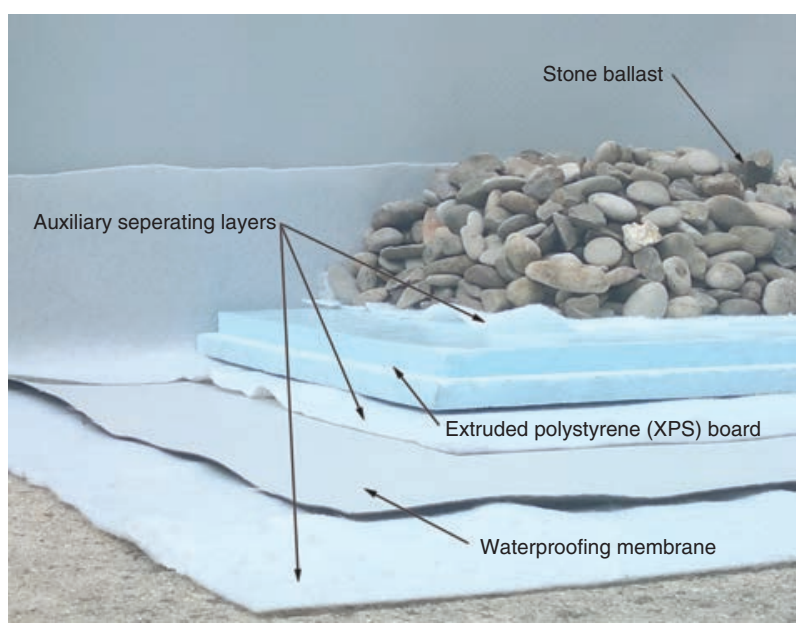

FIGURE 1. Image of a stone-ballasted inverted flat roof.

separating layers are designed to allow free movement and to provide physical and chemical protection to the materials.

The insulation material used in inverted flat roofs needs to have specific characteristics such as, no water absorption, compressive strength, and microorganism resistance, being the extruded polystyrene (XPS) board the unique alternative currently used.

There are some types of synthetic waterproofing membranes intended to be used in buildings and there are many manufacturers in the global market as for example: GAF (North America largest roofing manufacturer), ICOPAL headquartered in Denmark (annual turnover of approximately 1 bill $€$ ), FLAG-SOPREMA group (Europe), SIKA (headquartered in Switzerland and annual sales turnover of 5.75 billion Switzerland Francs in 2016). They all produce synthetic waterproofing membranes, but only of plasticized polyvinyl chloride (PVC-P) and thermoplastic polyolefin (TPO). Nevertheless, there is an important market of synthetic waterproofing membranes of EPDM, especially in America, where one of the main manufacturers is FIRESTONE building products, which additionally produces TPO.

Therefore, the most important synthetic waterproofing membranes for the building industry are: plasticized polyvinyl chloride (PVC-P), thermoplastic polyolefin (TPO) and ethylene propylene diene monomer (EPDM) waterproofing membranes.

XPS plates may interact with the plasticized polyvinyl chloride (PVC-P) waterproofing membrane in the inverted flat roof (2), deteriorating the materials and thus reducing the life cycle of the construction system. For this reason, the auxiliary separating layer -placed between the waterproofing membrane and the XPS- is of great importance as it reduces this effect. This is one of the reasons for placing 
auxiliary separating layers in flat roofs, to cut down degenerative interactions.

Some building roofing standards state the need to avoid interactions and incompatibilities between the different materials. This issue is mainly solved by placing auxiliary separating layers, for instance, in between XPS and waterproofing materials. Regulations state this, even between materials which are not clearly described as incompatibles.

Beforehand, the efficiency of auxiliary separating layers depends basically on their thickness and composition. This paper analyzes the effectiveness of several types and thickness of auxiliary separating layers in order to avoid incompatibilities in inverted flat roofs. Furthermore, the possible interactions between the extruded polystyrene (XPS) and two types of synthetic waterproofing membranes (TPO and EPDM) are also studied.

Sometimes flat roofs must resist a layer of soil with a significant thickness (green roofs), thicker pavements, extra loads or installations which are not placed on independent structures but directly over the roof. Installations such as: air conditioning, absorption and cooling units, solar thermal generation systems, etc. In these cases the pressure between materials is greater than usual, and XPS mitigates the overloads. This paper also analyzes the effect of the pressure between the materials and its consequences.

The pressures between materials of the most common ballasted roofs can be calculated adding the weights of the materials that the waterproofing membrane has over it, and dividing the result by a unit of area, giving the following pressures:

- Stone-ballasted roof with $5 \mathrm{~cm}$ thick of gravel $\approx$ $14.61 \mathrm{~g} / \mathrm{cm}^{2}$.

- Stone-ballasted roof with $10 \mathrm{~cm}$ thick of gravel $\approx 29.23 \mathrm{~g} / \mathrm{cm}^{2}$.

- Paved-ballasted roof with $8 \mathrm{~cm}$ thick of mortar and tiles or concrete $\approx 21.38 \mathrm{~g} / \mathrm{cm}^{2}$.

These values were reached considering: two layers of geo-textile of $300 \mathrm{~g} / \mathrm{m}^{2}$, XPS of $5 \mathrm{~cm}$ thick and a specific density of around $33 \mathrm{~kg} / \mathrm{m}^{3}$, river siliceous gravel of a particle size between $20-40 \mathrm{~mm}$ with a density of about $1700 \mathrm{~kg} / \mathrm{m}^{3}$ and pavements made of mortar and floor tiles or concrete with a specific density of around $2150 \mathrm{~kg} / \mathrm{m}^{3}$.

\section{STATE OF THE ART}

Most polymers are incompatible with each other (3). Furthermore, the materials usually placed in inverted flat roofs are mainly polymers, as for example the geo-textiles used as auxiliary separating layers are normally made of polymeric materials such as polyester or polypropylene. XPS is a polymeric foam, additionally there are different types of synthetic polymeric waterproofing membranes normally used in the building industry, such as the PVC-P waterproofing membranes.

PVC-P can contain a wide variety of additives (4), such as plasticizers, which increase the plasticity of the material. Plasticizers are included in the manufacture of PVC-P to increase its flexibility, workability or distensibility (5); besides plasticizers of plastic materials can move to another substance or material, such as food products, liquids (6), or even to another plastic (7), this phenomenon is known as plasticizers migration. Moreover, crude polystyrene in favorable conditions is capable of taking plasticizers contained in other plastics as it is the case of PVC-P (8).

Under normal weather conditions XPS interact with PVC-P waterproofing membranes in the inverted flat roof (9). This interaction can be summarized as the migration of plasticizers from PVC-P to XPS (2). This may be considered an incompatibility (10), as eventually PVC-P loses many of its properties -becoming stiffer and even shrinking- (11).

Other common types of synthetic waterproofing membranes are polyolefins, such as the thermoplastic polyolefin (TPO) and the ethylene propylene diene monomer (EPDM), which is an elastomer, viscoelastic amorphous thermo polymer (12). However, the interactions between these materials and the XPS in the inverted flat roof have not been described.

According to ASTM D-1418 - 17, EPDM is an $\mathrm{M}$-class rubber (13). The M class refers to the saturated backbone structure, which includes rubbers which have a saturated chain of a polymethylene type. EPDM materials have excellent resistance to heat, oxidation, ozone and weather aging due to their stable saturated polymer backbone structure. They have good electrical resistivity (as non-polar elastomers), as well as resistance to polar solvents, such as water, diluted acids, alkalis, phosphate esters and many ketones and alcohols (14). However, EPDM materials are totally unsuitable with petroleum based fluids such as all mineral oil products, lubricants, fuels, etc.

EPDM materials are divided into two types: sulfur-cured and peroxide-cured. The sulfur acceleration systems can obtain materials with heat resistance up to $130^{\circ} \mathrm{C}(15)$ with a better durability. The peroxide-cured compounds are suitable for higher temperatures, a heat resistance up to $160^{\circ} \mathrm{C}$ can be obtained with this system. The amorphous or low crystalline grades have excellent low temperature flexibility with glass transition points of about $-60^{\circ} \mathrm{C}(16)$. These polymers may include additions of fillers and plasticizers (17).

EPDM waterproofing membranes have been used in the low-slope roofing industry for over 40 
years and they do not have internal reinforcement. On the contrary, TPO waterproofing membranes do have internal reinforcement and have been used for more than 40 years in the Civil Engineering industry, especially for waterproofing of landfills, ponds and water canals. However, the excessive stiffness of these materials made them unsuitable for building roofings until 1991 (18).

Polyolefins can be defined as every synthetic resin made by olefins or alkenes polymerization. They are hydrocarbon molecules with at least one double carbon-carbon bond. Polyolefins are polymer molecules made using either free-radical, ionic initiators, inorganic (metal oxide) or organic-metallic catalysts (19). Each polymerization process produces a different Polyolefin type, being the linear high-molecular-weight thermoplastic polymers the ones mainly produced.

To a lesser extent than PVC-P, thermoplastic polyolefins do normally contain additives (such as stabilizers, inorganic and organic fillers, antioxidants, antistatic agents, etc.), but they do not contain plasticizers (20).

The thermoplastic polyolefins can be divided in two types: polyethylene and polypropylene, which in turn they are subdivided into several grades regarding their different applications. Commercial polyethylene resins are normally copolymers of ethylene, with varying fractions of $\alpha$-olefin comonomer, which changes the physical properties and applications of polyolefins. The most common $\alpha$-olefins are 1-butene, 1-hexene, and 1-octene (21).

The polypropylene resins are mostly isotactic materials nevertheless a few syndiotactic grades are also available. There are two principal types of Propylene copolymers: random propylene/ethylene copolymers, and impact propylene/ethylene copolymers (22).

The TPO waterproofing membranes used in the building industry are most often produced by a mixture of polyolefins which form a stable and flexible polymeric compound.

There is a low knowledge about what materials are really incompatible in flat roofs. Therefore, it is important to clarify the risks of placing -in close contact- certain materials, the quality of auxiliary separating layers to reduce interactions, and the conditions favoring these interactions. Flat roofs are often designed and built improperly because of this lack of knowledge, giving eventually less durability to the system.

Several researchers have studied the interactions and incompatibilities in flat roofs. A previous paper studied the importance of placing auxiliary separating layers in flat roofs, being of crucial importance for roofs' refurbishment (1). At some time, flat roofs need to be rebuilt, and frequently the new roof is built over the old one, consequently the new waterproofing material is placed over the existing waterproofing layer. In some of these cases the auxiliary separating layer is crucial to keep the integrity of the new waterproofing membrane. The interactions between XPS and PVC-P waterproofing membranes was previously analyzed testing an inverted flat roof (in use) (2) and testing in the laboratory all the materials with different configurations (9), including two types of geo-textiles as auxiliary separating layers. Finally, other paper analyzing the interactions between XPS and PVC-P was found, considering the deterioration of the PVC-P. This research analyzed, with a scanning electron microscope (SEM), the surface and the elemental composition of different samples (10).

The present study was conducted in Spain, specifically in the Madrid area, and unlike the previous papers, this article shows the results of several laboratory tests performed with XPS and synthetic waterproofing membranes of EPDM and TPO. It also analyzes the efficiency of six auxiliary separating layers (not previously tested) and studies the pressure effect on the interactions.

\section{OBJETIVE}

This study aims to enlarge the knowledge regarding the incompatibilities between the most important synthetic waterproofing materials and the extruded polystyrene used in inverted flat roofs. It also quantifies the pressure effect on the degradation of the PVC-P waterproofing membranes and explores the effectiveness of alternative auxiliary separating layers to reduce interactions and incompatibilities depending on their thickness and composition.

\section{MATERIALS AND METHODS}

The methodology followed unfolds in three experimental short-term tests (23) performed in the laboratory in order to obtain information about the different conditions of pressure and the behavior of the different types of materials used in the inverted flat roof. The first test analyzed the efficiency of different auxiliary separating layers in the inverted flat roof, the second test studied the pressure effect on the deterioration of a synthetic waterproofing membrane and the third test analyzed the possible interactions between XPS and the waterproofing membranes of EPDM and TPO.

The methodology followed was based on standard ISO 177:2016(24). This Standard describes a test were plastic materials are exposed to a heat for a period of time in order to determine the tendency of plasticizers to migrate from plastic. The tests were performed using different synthetic waterproofing membranes and XPS as the absorbent material of plasticizers.

The tests followed the procedure of ISO 177:2016 standard, but it was adapted to the conditions of the inverted flat roof, as the reference temperature set by the standard is $70{ }^{\circ} \mathrm{C}$. However at this temperature XPS may present thermal degradation (2). 
Moreover, the established absorbent material set by ISO 177 is a rubber disc, nevertheless these tests were performed with XPS instead of rubber in order to simulate an inverted flat roof cross section and because XPS is also capable of absorbing plasticizers (8). Also, the pressures of the tests performed were much lower than the one specified by the standard in order to make accurate tests and close to the conditions of the inverted flat roof.

The tests intend to study the efficiency of different auxiliary separating layers in identical conditions; to analyze the effect of the pressure between the samples on the degradation of the materials (in identical conditions and only varying the pressure in the different configurations); and finally to prove the compatibility of XPS and the waterproofing membranes of TPO and EPDM in a test based in the ISO 177:2016 standard and with identical conditions.

The general bases of the tests are described in Figure 2, were the materials involved, the interaction and the effect of the pressure are described. The materials tested were placed in close contact, and under defined conditions of pressure, temperature, and time. The mass loss of the samples after the test was recorded and becomes a measure of plasticizer migration. The more mass lost the greater damage in the waterproofing membrane.

The temperature of all the tests was $50{ }^{\circ} \mathrm{C}$, and every configuration was always tested three times. In the tests performed the XPS was IV type

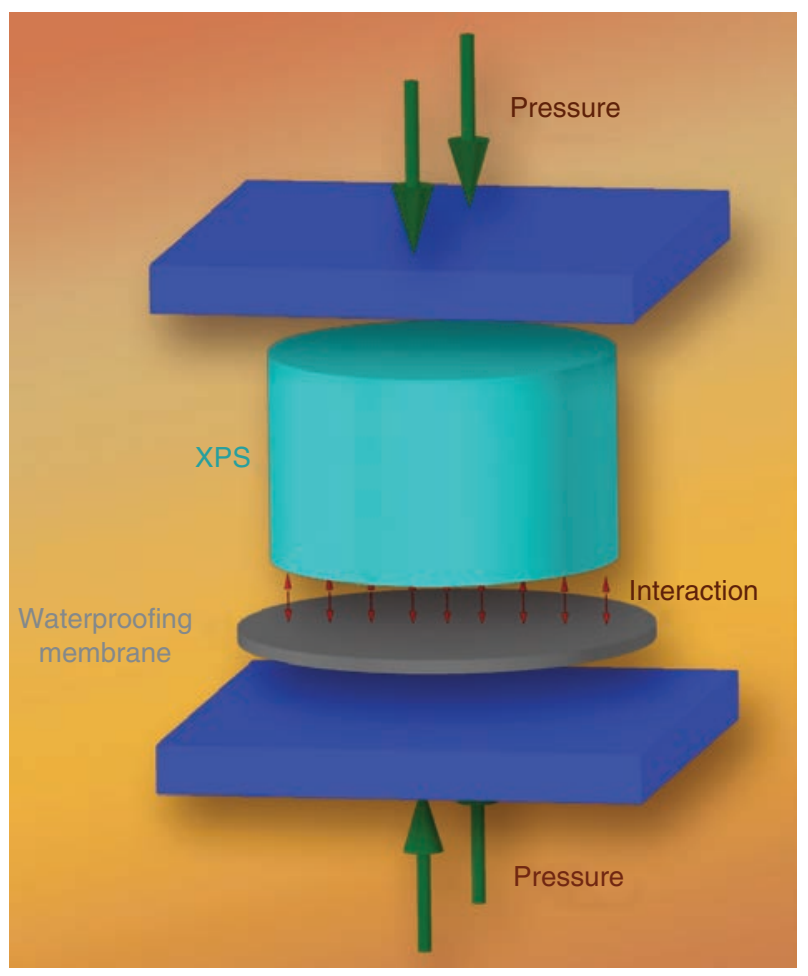

FIGURE 2. Schematic image describing the general rules of the tests.
ROOFMATE SL - $30 \mathrm{~mm}$, the cylindrical samples had $60 \mathrm{~mm}$ of diameter. The disc shaped waterproofing membranes samples had a diameter of $50 \mathrm{~mm}$. To weigh the samples, a scale with a $0.001 \mathrm{~g}$ of precision was used. The difference between the previous and the final mass would be the mass loss of this material. The results of every test and configuration are presented showing the average, the standard deviation and the $\mathrm{RSD} \%$ or relative standard deviation in percentage.

The details of the three different tests performed are shown in the next subsections.

\subsection{Analysis of auxiliary separating layers}

The first test analyzed the effectiveness of eight different types of auxiliary separating layers to avoid interactions and incompatibilities (six of them no tested before). The test was performed in a furnace during thirty days at $50{ }^{\circ} \mathrm{C}$ and with a pressure -between the samples- of $4.634 \mathrm{~g} / \mathrm{cm}^{2}$.

The 4.1 image in the superior part of the Figure 3 shows the details of this test, i.e. the same
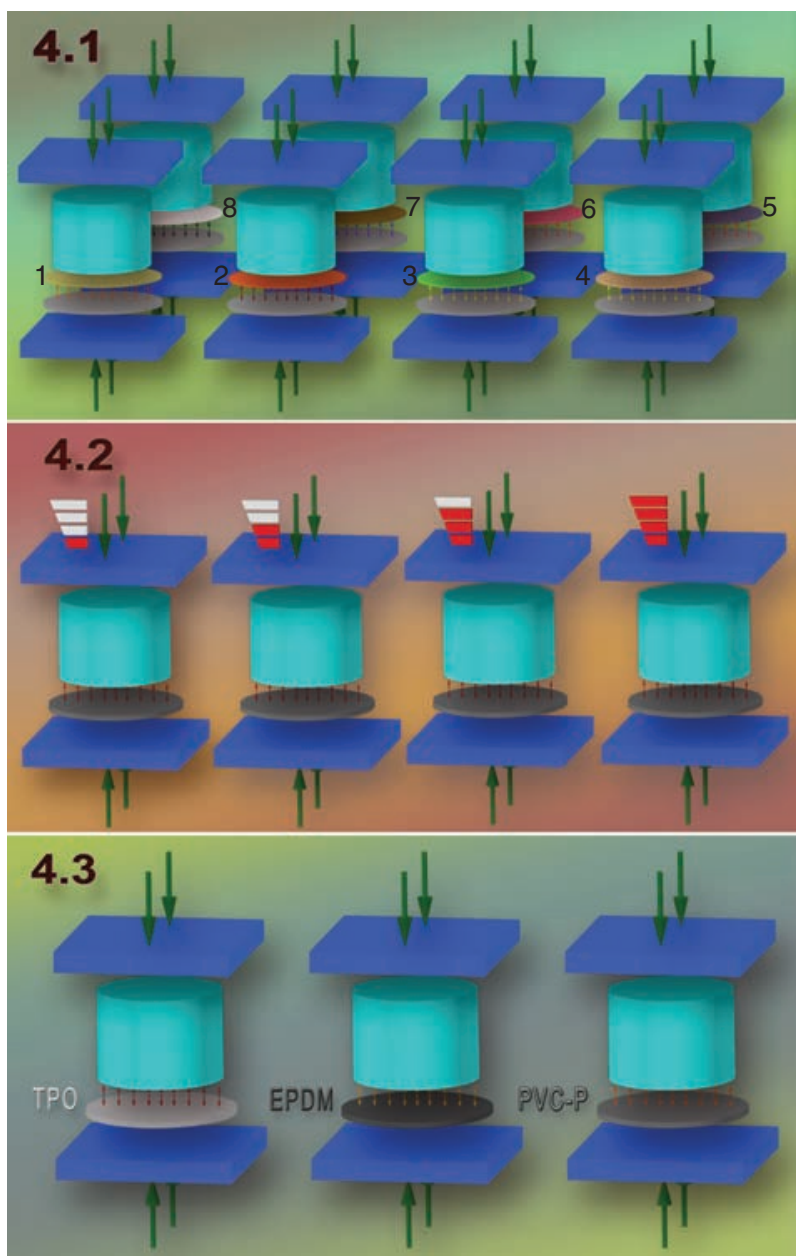

Figure 3. Schematic images describing the three tests performed. 
configuration presented in Figure 2, but including eight different types of auxiliary separating layers between the XPS and the synthetic waterproofing membranes, which in this test were made of PVC-P. The brands of the waterproofing membranes used were Sarnafil (C) G410 - 12 and Sikaplan (C) 12 G, every PVC-P sample was tested three times with each auxiliary separating layer. All waterproofing samples were weighed before placing them in the furnace, and after removing them.

The auxiliary separating layers were chosen to test all the possibilities offered by the UNE 104416 Standard (25). This Standard regulates the implementation of synthetic waterproofing systems in roofs. The samples of auxiliary separating layers had a circular shape with a diameter of $60 \mathrm{~mm}$.

Eight types of auxiliary separating layers were used: polyester geo-textile of $150 \mathrm{~g} / \mathrm{m}^{2}$ and $300 \mathrm{~g} /$ $\mathrm{m}^{2}$, polypropylene geo-textile of $150 \mathrm{~g} / \mathrm{m}^{2}$ and 300 $\mathrm{g} / \mathrm{m}^{2}$, polyethylene films of $70 \mathrm{~g} / \mathrm{m}^{2}(0.1 \mathrm{~mm})$ and $140 \mathrm{~g} / \mathrm{m}^{2}(0,2 \mathrm{~mm}) 4$ and 8 mills respectively according to ASTM D2103 standard (26), and finally two fiberglass felts of $80 \mathrm{~g} / \mathrm{m}^{2}$ and $160 \mathrm{~g} / \mathrm{m}^{2}$. The results were estimated by calculating the average of the mass loss values of the three samples tested in every configuration.

\subsection{Analysis of the pressure effect on the degradation of waterproofing membranes}

The second test studied the pressure effect on the degradation of synthetic waterproofing membranes in an inverted flat roof. It was carried out in a furnace during fifteen days at $50{ }^{\circ} \mathrm{C}$ and with a pressure (between the samples) of $4.634 \mathrm{~g} / \mathrm{cm}^{2}, 7.792 \mathrm{~g} / \mathrm{cm}^{2}$, $13.975 \mathrm{~g} / \mathrm{cm}^{2}$ and $24.092 \mathrm{~g} / \mathrm{cm}^{2}$.

Image 4.2 of Figure 3 presents four configurations in which the only variable is the pressure between the materials. The PVC-P membrane tested was Sikaplan (C) $12 \mathrm{G}$ and it was weighed before and after the test.

The results of every configuration were estimated as in the previous test, i.e. by calculating the average of the mass loss values of every configuration.

As well as the rate of plasticizer loss increases when the temperature rises (27), it is predictable that the greater pressure between the materials the higher interaction.

\subsection{Analysis of interactions between synthetic waterproofing membranes and XPS}

The last experimental test studied the interactions between three types of synthetic waterproofing membranes (two of them no tested in previous studies) and the XPS. The interactions between the PVC-P waterproofing membranes and the XPS were previously studied. These interactions generate over time plasticizers migration from PVC-P to XPS in normal conditions of any inverted flat roof (9). This phenomenon produces significant deterioration in the waterproofing membrane, including: plasticizer migration, dehydrochlorination and oxidative degradation (10). The test developed in this part intends to analyze possible interactions between the XPS and the synthetic waterproofing membranes of EPDM and TPO. Nevertheless this test also includes samples of PVC-P in order to get general findings of the main synthetic waterproofing membranes in the same experiment and with identical conditions, since PVC-P and XPS were previously tested but mainly in different conditions of temperature and time. The image 4.3 in Figure 3 describes the experiment.

The test was performed with a pressure between the samples of $4.634 \mathrm{~g} / \mathrm{cm}^{2}$, in the same furnace and during fifteen days at $50{ }^{\circ} \mathrm{C}$. The synthetic waterproofing membranes analyzed were: Sarnafil (R) G410-12 and Sikaplan (B) 1,2 G Sika (PVC-P membranes); Sikaplan ${ }^{\circledR}$ WT 4220-15C - Sika and Sarnafil@ TS 77-12 - Sarnafil (TPO membranes); and finally the EPDM Giscolene $200-\mathrm{M}$ - Giscosa - Firestone.

Polyolefins, as many other polymers, are not products defined by particular specifications. Each manufacturer offers a wide variety of products with different composition and properties, adapted to the specific applications in which the material will be finally used. Thus, polyolefins must be considered as varied materials in their properties as could be wood or steel. As a Polyolefin, the composition of TPO waterproofing membranes can present differences depending on the manufacturer. TPO, theorically, do not have plasticizers in their composition.

The composition of EPDM may include substances which can be considered as plasticizers, such as paraffinic oil and ester plasticizer -which in its simplest concept is a high-boiling organic solvent that when it is added to an elastomeric polymer it reduces the stiffness and allows an easier processing (5)-. The results are shown calculating the average of mass loss values of the three cases analyzed.

\section{RESULTS AND DISCUSSION}

\subsection{Analysis of auxiliary separating layers}

This section presents the results of the tests performed in the furnace during thirty days at $50{ }^{\circ} \mathrm{C}$, offering mean values, standard deviation and RSD\% of the results. The efficiency of every auxiliary separating layer is measured comparing the results of mass loss with the ones obtained by the samples in direct contact with XPS. The results of this test are shown in the Table 1.

There is no relation between the brands of the synthetic waterproofing membranes tested and the standard deviation values. However, this is not the case of the configuration of the samples. The configuration 
TABLE 1. Mean values of mass loss, standard deviation and $\mathrm{RSD}$ in percentage. Test in the furnace during thirty days at $50^{\circ} \mathrm{C}$.

\begin{tabular}{|c|c|c|c|}
\hline \multicolumn{4}{|c|}{ Configuration of the samples } \\
\hline \multicolumn{4}{|c|}{ Direct contact between XPS and PVC-P } \\
\hline PVC-P Membranes & Average & $\sigma$ & RSD\% \\
\hline $1^{\text {st }}$ Brand & 0.044 & 0.00252 & $5.763 \%$ \\
\hline $2^{\text {nd }}$ Brand & 0.041 & 0.00208 & $5.119 \%$ \\
\hline
\end{tabular}

Auxiliary separating layer of Polyester Geo-textile $300 \mathrm{~g} / \mathrm{m}^{2}$

\begin{tabular}{lccc}
\hline PVC-P Membranes & Average & $\boldsymbol{\sigma}$ & RSD $\%$ \\
\hline $1^{\text {st }}$ Brand & 0.007 & 0.00058 & $8.660 \%$ \\
$2^{\text {nd }}$ Brand & 0.006 & 0.00058 & $9.116 \%$
\end{tabular}

Auxiliary separating layer of Polypropylene Geo-textile $300 \mathrm{~g} / \mathrm{m}^{2}$

\begin{tabular}{lccc}
\hline PVC-P Membranes & Average & $\boldsymbol{\sigma}$ & RSD $\%$ \\
\hline $1^{\text {st }}$ Brand & 0.011 & 0.00058 & $5.413 \%$ \\
$2^{\text {nd }}$ Brand & 0.008 & 0.00000 & $0.000 \%$
\end{tabular}

Auxiliary separating layer of Polyester Geo-textile $150 \mathrm{~g} / \mathrm{m}^{2}$

\begin{tabular}{lccc}
\hline PVC-P Membranes & Average & $\boldsymbol{\sigma}$ & RSD $\%$ \\
\hline $1^{\text {st }}$ Brand & 0.006 & 0.00058 & $9.116 \%$ \\
$2^{\text {nd }}$ Brand & 0.007 & 0.00058 & $7.873 \%$
\end{tabular}

Auxiliary separating layer of Polypropylene Geo-textile $150 \mathrm{~g} / \mathrm{m}^{2}$

\begin{tabular}{lccc}
\hline PVC-P Membranes & Average & $\boldsymbol{\sigma}$ & RSD $\%$ \\
\hline $1^{\text {st }}$ Brand & 0.010 & 0.00058 & $5.973 \%$ \\
$2^{\text {nd }}$ Brand & 0.009 & 0.00058 & $6.662 \%$
\end{tabular}

Auxiliary separating layer of Polyethylene film $140 \mathrm{~g} / \mathrm{m}^{2}$

\begin{tabular}{lccc}
\hline PVC-P Membranes & Average & $\boldsymbol{\sigma}$ & RSD \% \\
\hline $1^{\text {st }}$ Brand & 0.022 & 0.00208 & $9.321 \%$ \\
$2^{\text {nd }}$ Brand & 0.023 & 0.00058 & $2.547 \%$
\end{tabular}

Auxiliary separating layer of Polyethylene film $70 \mathrm{~g} / \mathrm{m}^{2}$

\begin{tabular}{lccc}
\hline PVC-P Membranes & Average & $\boldsymbol{\sigma}$ & RSD $\%$ \\
\hline $1^{\text {st }}$ Brand & 0.021 & 0.00208 & $9.758 \%$ \\
$2^{\text {nd }}$ Brand & 0.024 & 0.00200 & $8.333 \%$
\end{tabular}

Auxiliary separating layer of Fiberglass felt film $160 \mathrm{~g} / \mathrm{m}^{2}$

\begin{tabular}{lccc}
\hline PVC-P Membranes & Average & $\boldsymbol{\sigma}$ & RSD $\%$ \\
\hline $1^{\text {st }}$ Brand & 0.007 & 0.00058 & $7.873 \%$ \\
$2^{\text {nd }}$ Brand & 0.006 & 0.00058 & $9.116 \%$
\end{tabular}

Auxiliary separating layer of Fiberglass felt film $80 \mathrm{~g} / \mathrm{m}^{2}$

\begin{tabular}{lccc}
\hline PVC-P Membranes & Average & $\boldsymbol{\sigma}$ & RSD $\%$ \\
\hline $1^{\text {st }}$ Brand & 0.006 & 0.00058 & $9.116 \%$ \\
$2^{\text {nd }}$ Brand & 0.008 & 0.00058 & $7.531 \%$ \\
\hline
\end{tabular}

with the greatest values of standard deviation is: direct contact between XPS and PVC-P, followed by polyethylene films. The rest of the values are similar to each other. When the mass loss of the samples decreases, the results are closer to each other, and consequently standard deviation values are lower. The RDS \% values showed in Table 1 are between $0 \%$ and $9.116 \%$, and they do not follow any visible rule. The precision of the values are within the requirements of the ISO 177 standard (24).
To comply with the requirements of the ISO 177 the mean value of the results has to follow a rule. Every configuration was tested three times with different samples of the same material. The mean deviation of the three weights could not be greater than $10 \%$ when compared to each single weight. This norm was applied and achieved in all the tests presented in this study. When the results were unacceptable the test was repeated.

In order to clarify the results, Figure 4 presents a graph with the mean values of mass loss obtained for every configuration in percentage. The materials of identical composition obtained results which were quite similar to each other, independently of their mass. This is an important factor to take into account, as the UNE 104416 standard (25) indicates the minimum weights per square meter of some of these auxiliary separating layers to avoid incompatibilities. After considering the results, the weight or the thickness of these materials are not as important, at least with low pressures.

The results of the two brands tested were quite similar, in most of the cases there were small differences between them for the different configurations. The most effective auxiliary separating layer was the polyester geo-textile, followed by the fiberglass felts, the polypropylene geo-textile and finally the polyethylene films which were the least efficient.

Therefore, any of these auxiliary separating layers can be used to avoid the interactions, but all of them to a greater or lesser extent only reduce the interactions, they do not avoid them completely.

Two of these auxiliary separating layers were previously tested in another study (2), specifically geo-textiles of polyester and polypropylene of 300 $\mathrm{g} / \mathrm{m}^{2}$, but they were tested in different conditions of time and temperature. Therefore, the results cannot be compared in identical conditions, as the comparison would not add anything significant. The findings of this previous paper show that temperature and time affected significantly to the mass loss of the samples tested. The present article confirm those results being more important the temperature factor than time. The previous paper concluded that the unique manner to avoid interactions is placing metallic barriers between the synthetic waterproofing membrane and the XPS, for instance an aluminum foil of $0.013 \mathrm{~mm}$ thick would be enough.

The present study intended to test new materials for this end, and specially to analyze the relation between the thickness and the efficiency of these materials. Thus, only fiberglass felts improved the efficiency of polypropylene geo-textiles, but again the most recommendable auxiliary separating layer currently available in the market would be the polyester geo-textile. Nevertheless the thickness of this material is not important to improve the performance of the inverted flat roof, at least at low pressures. Currently the manufacturers of the building 


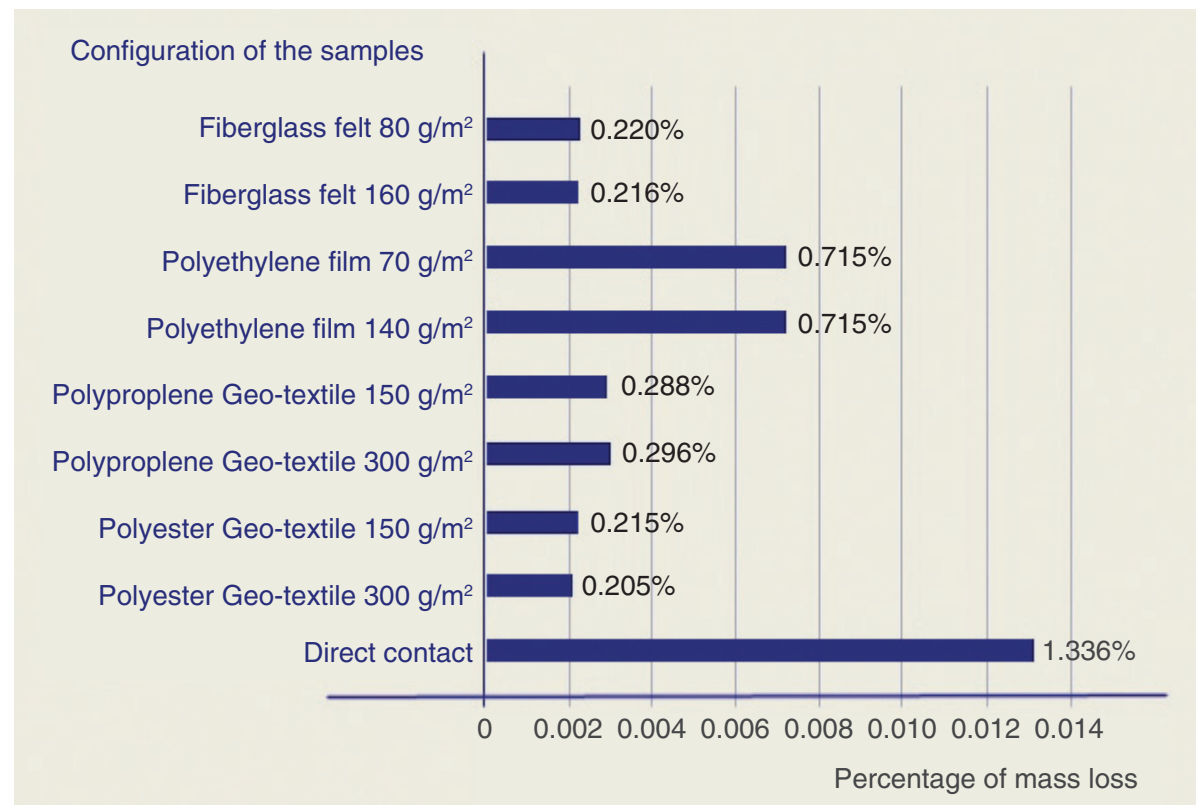

FIGURE 4. Mean values of mass loss for every tested configuration (in percentage).

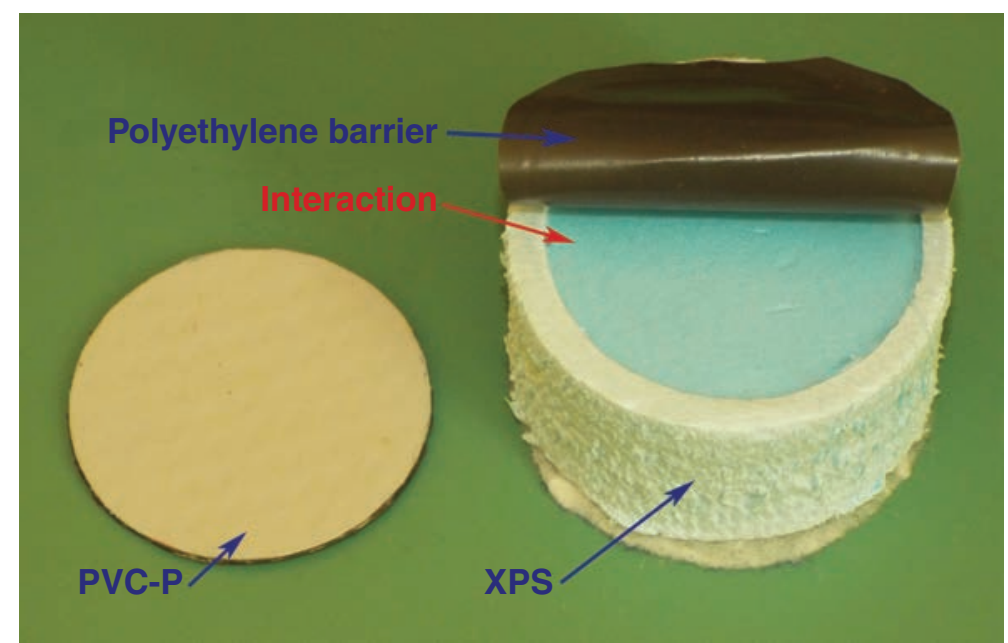

FIgURE 5. Interaction between the samples of PVC-P and XPS, with a Polyethylene barrier in between during the test.

industry do not offer metallic barriers to improve the performance of the inverted flat roof.

It is noticed that polyethylene films do not have a good response reducing the mass loss, but also they do not prevent interactions. These materials are not suitable to be used as auxiliary separating layers. Figure 5 shows the interaction produced in the XPS surface even with a polyethylene barrier is used.

\subsection{Analysis of the pressure effect on the degradation of waterproofing membranes}

The results for this test in the draft furnace during fifteen days at $50^{\circ} \mathrm{C}$ are shown in Table 2, which are presented offering mean values, standard deviation and $\mathrm{RSD} \%$ of the results.
The results of Table 2 show a clear increase in the mass loss of the samples depending on the pressure applied. In this case, values of the standard deviation and RSD\% increase as the pressure applied on the sample increases.

Figure 6 shows the relation between the pressure applied and the mass loss for each sample. The relation between these factors is almost lineal, indicating that the more pressure the more mass loss, and consequently the risk of deterioration of this synthetic waterproofing membrane increases when the pressure rises. Nevertheless, the relation between the pressure and the mass loss in the sectors between the pressures increase slightly and consequently the slope of the linear relation 
increases as well, which might indicate that probably at higher pressures the interaction could be much greater.

The most common pressures for the materials of the ballasted flat roofs are approximately between $14 \mathrm{~g} / \mathrm{cm}^{2}$ and $21 \mathrm{~g} / \mathrm{cm}^{2}$, however there are many factors in the building industry that can increase these pressures, such as the type and thickness of the ballast and the use of the roof (gardens, parking lots at the ground level, etc.).

Previous studies did not analyze the pressure effect on the deterioration of the materials. The present paper intend to study the importance of the pressure between the materials for waterproofing deterioration, and indeed this effect is very important for the durability of synthetic waterproofing membranes (incompatibles with the XPS), and consequently the pressure between materials may affect significantly to the life cycle of the inverted flat roof.

\subsection{Analysis of interactions between synthetic waterproofing membranes and XPS}

This experiment was performed in the draft furnace during fifteen days at $50{ }^{\circ} \mathrm{C}$ the results are shown in Table 3 offering mean values, standard deviation and RSD values in percentage.

TABLE 2. Average results, standard deviation and $\mathrm{RSD} \%$ of the test performed in the draft furnace during fifteen days at $50{ }^{\circ} \mathrm{C}$.

\begin{tabular}{|c|c|c|c|}
\hline \multicolumn{4}{|c|}{ Configuration of the samples } \\
\hline \multicolumn{4}{|c|}{ Direct contact between XPS and PVC-P } \\
\hline Pressures & Average & $\sigma$ & RSD $\%$ \\
\hline $4.634 \mathrm{~g} / \mathrm{cm}^{2}$ & 0.032 & 0.00082 & $2.552 \%$ \\
\hline $7.792 \mathrm{~g} / \mathrm{cm}^{2}$ & 0.034 & 0.00183 & $5.370 \%$ \\
\hline $13.975 \mathrm{~g} / \mathrm{cm}^{2}$ & 0.037 & 0.00216 & $5.839 \%$ \\
\hline $24.092 \mathrm{~g} / \mathrm{cm}^{2}$ & 0.042 & 0.00374 & $8.909 \%$ \\
\hline
\end{tabular}

In spite of the fact that the mass loss of PVC-P was more than double of EPDM, both materials had a significant mass loss. However TPO waterproofing membranes underwent a tiny mass loss after the test, this was predictable, since these materials do not contain plasticizers. TPO waterproofing membranes may have a diverse composition, the mass loss registered for this material after the test could be related with volatile substances contained in it. In fact, the ISO 177 standard indicates that these substances can be released in this test.

Except for the results obtained in TPO membranes, the values of standard deviation and RSD\%, were approximately within the range of the previous tests carried out. In the case of TPO, the mass loss was very small. When this test is performed with TPO samples, a scale with a $0.0001 \mathrm{~g}$ of precision should be used or even other more precise. The ISO 177 standard indicates to use a scale with 0.001 $\mathrm{g}$ of precision nonetheless in this case, it was not enough. It is highly complicated to fulfill the precision requirements of the standard when the weights of the samples fluctuate only $0.001 \mathrm{~g}$.

TABle 3. Average, standard deviation and RSD $\%$ of the results. Test in the draft furnace during fifteen days at $50^{\circ} \mathrm{C}$.

\begin{tabular}{lccc}
\hline \multicolumn{4}{c}{ Configuration of the samples } \\
\hline \multicolumn{4}{c}{ Direct contact between XPS and PVC-P } \\
\hline PVC-P Membranes & Average & $\sigma$ & RSD $\%$ \\
$1^{\text {st }}$ Brand & 0.032 & 0.00200 & $6.250 \%$ \\
$2^{\text {nd }}$ Brand & 0.032 & 0.00321 & $9.942 \%$ \\
\hline TPO Membranes & Average & $\sigma$ & RSD $\%$ \\
\hline $1^{\text {st }}$ Brand & 0.001 & 0.00000 & $0.000 \%$ \\
$2^{\text {nd }}$ Brand & 0.001 & 0.00000 & $0.000 \%$ \\
\hline EPDM Membrane & Average & $\sigma$ & RSD $\%$ \\
\hline $1^{\text {st }}$ Brand & 0.015 & 0.00115 & $7.531 \%$ \\
\hline
\end{tabular}

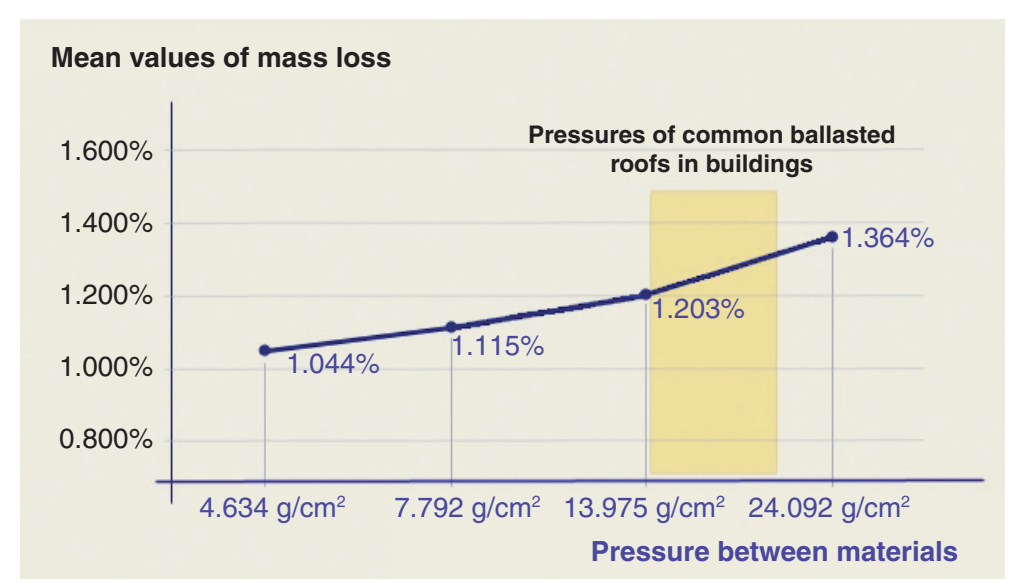

FIGURE 6. Relation between the pressures applied and the mass loss of the samples in percentage. 


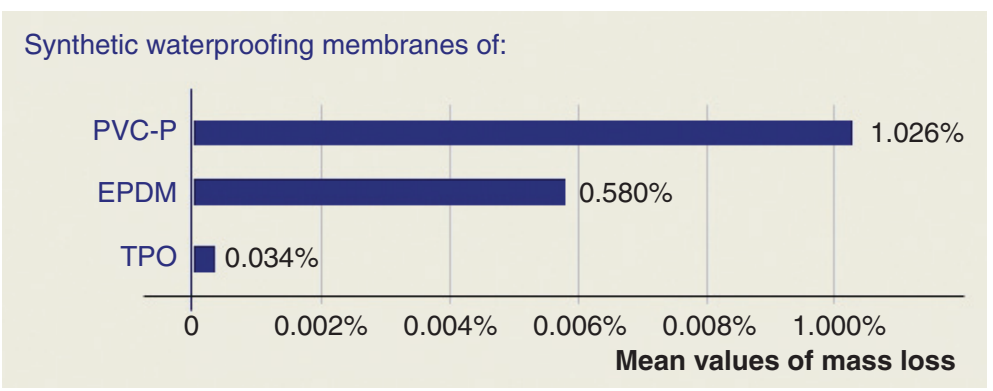

FIGURE 7. Mean values of mass loss in percentage of the synthetic waterproofing membranes tested.

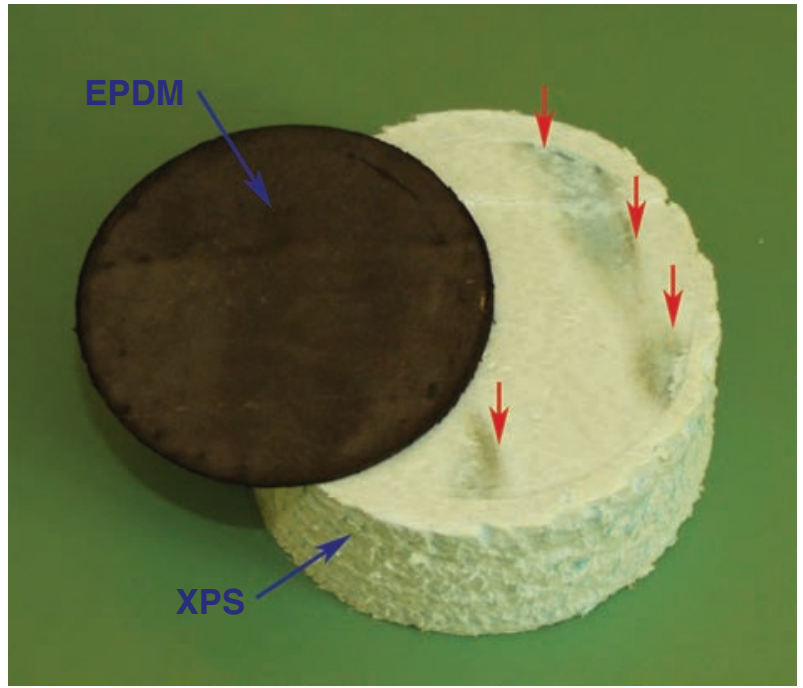

FIGURE 8. Image of a sample of EPDM waterproofing membrane and the traces of the interaction with the XPS, which are pointed out with red arrows on its surface.

The figure 7 shows the mean values in percentage of the mass loss of every type of synthetic waterproofing membrane tested.

When PVC-P interact with XPS in the inverted flat roof the polystyrene foam undergo a transformation in contact with PVC-P, this phenomenon was previously studied (2). The waterproofing membrane of EPDM lost significant mass in direct contact with the XPS, in this process the material lost additives and this circumstance undoubtedly deteriorates the material in the long term. Additionally, both materials interact and the remains of this interaction are pointed out with red arrows in the Figure 8.

By contrast, in PVC-P waterproofing membranes, the interaction between EPDM and XPS does not follow a uniform pattern. The traces of the interaction are spread on the surface of the XPS sample randomly. Every sample tested had similar behavior, and in all of the cases the traces or remains of interaction appeared on the surface of the XPS sample.

The waterproofing membranes of PVC-P were previously tested in direct contact with XPS (2). The first experimental part of this previous paper tested three different brands of PVC-P in direct contact with XPS during seven and fifteen days at $70{ }^{\circ} \mathrm{C}$. The mean values of mass loss were: $2.179 \%$ in the test during seven days, and $2.643 \%$ after fifteen days $\left(1.026 \%\right.$ after fifteen days and at $50{ }^{\circ} \mathrm{C}$ in the present study), consequently time is an important factor to take into account, but temperature is much more important for the deterioration of waterproofing membranes.

The second experimental part, of the previous paper above-mentioned, tested nine different brands of PVC-P in direct contact with XPS, during fifteen days at $50{ }^{\circ} \mathrm{C}$, i.e. identical conditions with the present study (the pressure between materials was also the same). In this case the mean value of mass loss was $0.864 \%$, and the nine brands ranged from $0.576 \%$ to $1.199 \%$ of mass loss. The result of the present part of the study $(1.026 \%)$ is within the range stablished by the previous research work. Moreover, the result of mass loss of the brand tested with identical pressure $\left(4.634 \mathrm{~g} / \mathrm{cm}^{2}\right)$-in section 5.2- is $1.044 \%$, which is also within that previous range. The composition of PVC-P waterproofing membranes varies widely depending on the manufacturer. Additives included in the manufacturing process have a special role in the results of mass loss of every brand studied.

The goal of this part of the study is to analyze the interaction between XPS and the waterproofing membranes of TPO and EPDM in the inverted flat roof, and to establish the incompatibility grade in comparison with PVC-P, which was already previously analyzed in depth.

\section{CONCLUSIONS}

The auxiliary separating layers must be placed always in the inverted flat roof. This is advisable even with compatible materials in order to provide free movement and physical protection to the materials.

The Polyester geo-textile is the best option to be used in inverted flat roofs. However, this material does not offer good resistance to the alkalinity of cement, so for the pavement of roofs the best option is the Polypropylene geo-textile. 
The Fiberglass felts provide good protection to reduce interactions. However these materials are not commonly used for this purpose and the material should be properly tested before using it. The microorganism resistance is not totally clear.

The Polyethylene films cannot be used as auxiliary separating layers in the inverted flat roof since they are not effective to prevent the deteriorative interactions.

At low pressures, the mass per square meter of auxiliary separating layers of identical composition is not decisive to cut down interactions. The results obtained are very close to each other independently on the thickness of the auxiliary separating layers analyzed.

There is a clear relation between the pressure applied on the materials of the inverted flat roof and the interaction between them. The more pressure the more chance for a degenerative interaction.

The inverted flat roofs with loads that apply greater pressure than usual have to dispose efficient auxiliary separating layers to separate the waterproofing membrane from XPS.

The waterproofing membrane of EPDM is incompatible with XPS, thus this material must be properly separated to enlarge the life cycle of the roof.

The waterproofing membrane of TPO is compatible with the XPS. However, it is advisable to use auxiliary separating layers to get physical protection and independence of the movements.

The temperature is crucial for the deterioration of incompatible waterproofing membranes in the inverted flat roof. For this reason, in this construction system, thicker XPS plates would reduce the interaction, since it would also reduce the temperature in the contact surface of both materials.

\section{REFERENCES}

1. Pedrosa, A.; Río, M. del (2013) Rehabilitation of flat roofs, concepts, minoration of incompatibilities and interactions. International Conference on Construction Research. Vivienda, pasado, presente y futuro. Instituto de Ciencias de la Construcción Eduardo Torroja, Madrid, Spain, CSIC, 173. http://digital.csic.es/bitstream/10261/108575/1/ Abstracts_and_Proceedings_\%20JORNADAS\%202013. pdf.

2. Pedrosa, A.; Río, M. del; Fonseca, C. (2014) Interaction between plasticized polyvinyl chloride waterproofing membrane and extruded polystyrene board, in the inverted flat roof. Mater. Construcc. 64 [316]. https://doi.org/10.3989/ mc.2014.008913

3. Buckley, D. J. (1967) Aspects of polymer compatibility. Transactions of the New York Academy of Sciences, 29: 735-747. https://doi.org/10.1111/j.2164-0947.1967. tb02297.x

4. Wilkes, C..E.; Summers, J.W.; Daniels, C.A.; Berard, M.T. (2005) PVC Handbook, Hanser Publishers, Munich, ISBNs $9781569903797 \mathrm{http}: / / \mathrm{www} \cdot h a n s e r p u b l i c a t i o n s$. com/Products/205-pvc-handbook.aspx

5. ASTM D883-12e1. (2012) Standard Terminology Relating to Plastics, ASTM International, West Conshohocken, PA, 2012, www.astm.org; Developed by Subcommittee:
D20.92; Book of Standards Volume: 08.01; https://doi. org/10.1520/D0883-12E01

6. Pedersen, G.A.; Jensen, L.K.; Fankhauser, A.; Biedermann, S.; Petersen, J.H.; Fabech, B. (2008) Migration of epoxidized soybean oil (ESBO) and phthalates from twist closures into food and enforcement of the overall migration limit. Part A: Chemistry, Analysis, Control, Exposure \& Risk Assessment Food Additives \& Contaminants, 25, 503-510. https://doi.org/10.1080/02652030701519088.

7. Papakonstantinou, V.; Papaspyrides, C.D. (1994) Plasticizer migration from plasticized into unplasticized poly (vinyl chloride). J. Vinyl Technology, 16, [4192-196]. https://doi.org/10.1002/vnl.730160404.

8. Marcilla, A.; Garcia, S.; Garcia-Quesada, J.C. (2008) Migrability of PVC plasticizers. Polymer Testing, 27. 221233, ISSN 0142-9418 Chemical Engineering Department, University of Alicante, https://doi.org/10.1016/j.polymertesting.2007.10.007.

9. Pedrosa, A.; Río, M. del; Fonseca, C. (2012) Durability analysis of PVC-P membrane in inverted flat roof. Coinvedi, $2^{\text {nd }}$ International Conference on Construction and Building Research, Springer, 515-521, Escuela Técnica Superior de Ingeniería de Edificación. Universitat Politècnica de València. Valencia, Spain. https://doi. org/10.1007/978-94-007-7790-3_62.

10. Pedrosa, A.; Río, M. del (2017) Comparative scanning electron microscope study of the degradation of a plasticized polyvinyl chloride waterproofing membrane in different conditions. Mater. Construcc. 67 [325] e109. https://doi. org/10.3989/mc.2017.08915

11. Giroud, J.P. (1995) Evaluation of PVC geomembrane shrinkage due to plasticizer loss. Geosynthetics International Industrial Fabrics Association International, 2 [6], 1099-1113. https://doi.org/10.1680/gein.2.0047

12. Green, M. M.; Wittcoff, H.A. (2003). Organic Chemistry Principles and Industrial Practice. Weinheim. Germany: Wiley-VCH Verlag GmbH , p. 170.

13. ASTM D1418-17 (2017) Standard Practice for Rubber and Rubber Latices-Nomenclature, ASTM International, West Conshohocken, PA, www.astm.org, https://www. astm.org/Standards/D1418.htm

14. Chandrasekaran, C. (2017) Anticorrosive Rubber Lining. A Practical Guide for Plastics Engineers. Elsevier. William Andrew applied science publisher. Oxford. United Kingdom. https://www.elsevier.com/books/ anticorrosive-rubber-lining/chandrasekaran/978-0-32344371-5.

15. Douglas, K. L. (2005). Elastomers. Handbook of sulphuric acid manufacturing. Richmond Hill, Canada: DKL Engineering. Inc. pp. 16-116, ISBN 9780973899207.

16. Bukhina, M.F.; Kurlyand, S.K. (2007) Low-Temperature Behaviour of Elastomers, New concepts in polymer science, CRC Press, Leiden - Boston, https://www.crcpress.com/Low-Temperature-Behaviour-of-Elastomers/ Bukhina-Kurlyand/p/book/9789004157200

17. Karpeles, R.; Grossi, A. V. (2001) "EPDM Rubber technology", Handbook of Elastomers, $2^{\text {nd }}$ Ed., Anil K. Bhowmick and Howard L. Stephens [Editors], pp. 845-876, Marcel Decker, Inc., New York.

18. Beer, H. R.; Mayr A. (2008). Flexible Polyolefin Roofing Membranes: 15 Years Of Field. Experience. Durability of building materials and components 11: Proceedings of the Eleventh International Conference on Durability of Building Materials and Components, 11DBMC, Istanbul, Turkey, 11-14. Durability of systems and components in buildings \& response of building elements to environmental loads, Vol 3.

19. Al-Ali AlMa'adeed, M.; I. Krupa, I. (2016). Polyolefin Compounds and Materials. Switzerland, Springer International Publishing, Springer Series on Polymer and Composite Materials, https://doi.org/10.1007/978-3319-25982-6_2.

20. Tolinski, M. (2015) Additives for Polyolefins. Getting the Most Out of Polypropylene, Polyethylene and TPO. Elsevier - William Andrew Publishing, Oxford, https://doi. org/10.1016/B978-0-323-35884-2.00021-1. 
21. Soares, J. B. P.; McKenna T. F. L. (2012) Polyolefin Reaction Engineering. Wiley-VCH Verlag $\mathrm{GmbH} \& \mathrm{Co}$ KGaA. Weinheim, Germany. https://doi.org/10.1002/ 9783527646944.fmatter

22. Karian, H.G. (2003) Handbook of Polypropylene and Polypropylene Composites, RhTech, INC, Whitmore Lake, Michigan, USA, Marcel Dekker, New York, CRC Press. https://doi.org/10.1201/9780203911808.ch19

23. Ortega, JJ; Blanco, M.; Cuevas, A. (1984) Acción de las radiaciones U.V. sobre el poli (cloruro de vinilo) flexible. Mater. Construcc. 196, [34]. https://doi.org/10.3989/ mc.1984.v34.i196.937.

24. ISO 177 (2016) Plastics - Determination of migration of plasticizers. International Organization for Standardization. Technical Committee ISO/TC 61/SC 6. Ageing, chemical and environmental resistance, ICS: 83.080.01 Plastics in general. https://www.iso.org/standard/70279.html.
25. UNE 104416 (2009). Synthetic materials. Waterproofing roofing systems made of membranes with flexible synthetic sheets. Instructions, control, use and maintenance. ICS 91.100.50-20 / Materiales sintéticos. AEN/CTN 104 Materiales impermeabilizantes para la construcción. http:// webpre.aenor.com/normas-y-libros/buscador-de-normas/ une $/$ c $=$ N0042729

26. ASTM D2103-15. (2015) Standard Specification for Polyethylene Film and Sheeting, ASTM International, West Conshohocken, PA, Book of Standards Volume: 08.01. http://www.astm.org/cgi-bin/resolver.cgi?D2103-15.

27. Su, X.; Song, J.; Qiu, Z-L.; Ru, H. (2012) The Temperature Impact on Migration of Four Kinds of Plasticizer in Food Packaging PVC Materials. Food Research and Development, Issue 1, Page 190-192. Food Science College, Shenyang Agriculture University, Shenyang Liaoning, China. http://en.cnki.com.cn/Article_en/CJFDTOTALSPYK201201052.htm 